\title{
Influences of Different Ectopic Fermentation Bed Fillers of Human Excreta on the Soil Properties and Growth of Chinese Pakchoi
}

Jiabin Li

IESDA CAAS: Chinese Academy of Agricultural Sciences Institute of Environment and Sustainable Development in Agriculture

Xue Liu

IESDA CAAS: Chinese Academy of Agricultural Sciences Institute of Environment and Sustainable Development in Agriculture

Changxiong Zhu

IESDA CAAS: Chinese Academy of Agricultural Sciences Institute of Environment and Sustainable Development in Agriculture

Liangguo Luo

IESDA CAAS: Chinese Academy of Agricultural Sciences Institute of Environment and Sustainable Development in Agriculture

\section{Zhuobo Chen}

IESDA CAAS: Chinese Academy of Agricultural Sciences Institute of Environment and Sustainable Development in Agriculture

Shan Jin

IESDA CAAS: Chinese Academy of Agricultural Sciences Institute of Environment and Sustainable Development in Agriculture

Bing Geng ( $\square$ gengbing2000@126.com )

Chinese Academy of Agricultural Sciences

\section{Research Article}

Keywords: Human feces, Black water, Ectopic fermentation bed system, Resource recovery, Biofertilizer

Posted Date: March 7th, 2022

DOI: https://doi.org/10.21203/rs.3.rs-1364666/v1

License: (c) (1) This work is licensed under a Creative Commons Attribution 4.0 International License. Read Full License 


\section{Abstract}

The reuse of human excreta as biofertilizer resources offers a new option for meeting the growing demand for food and addressing the scarcity of soil productivity. Feces and black water are two prevalent forms of human excreta, both of which contain potentially harmful substances and therefore need to be treated in an environmentally sound manner by appropriate means. Ectopic fermentation bed systems (EFSs) seem to be a new technique for effective human excreta management and the production of biofertilizers using decomposed fillers. Therefore, the objective of this study was to evaluate and compare the nutrient content and fertilizer potential of decomposed fills after treatment of human feces and black water by an EFS under different application conditions. The results showed that the application of an appropriate proportion of fillers was beneficial to promote the growth of pakchoi, improve the yield and quality of pakchoi, and enhance soil fertility. The safe production requirements of agricultural products can be met as long as a reasonable filler application rate is maintained, with human feces fillers controlled within $5 \%$ and black water fillers controlled within $10 \%$. The main factors affecting the yield and quality of pakchoi in this study were soil properties, especially soil EC. These findings help to better clarify the agronomic value of human excreta; however, the effects of long-term filler application need to be further explored.

\section{Introduction}

For thousands of years, farmers around the world have relied on human excreta as fertilizer. The World Health Organization (WHO) has pointed out that treated excreta can be used as a soil conditioner and in agricultural production to achieve water conservation and rational utilization and to protect human health (Avvannavar and Mani 2007). Most of the nutrients in food are excreted with feces and urine, except for a small portion absorbed by the body. According to statistics, human excreta contains $5-10 \%$ organic matter, $0.5-0.8 \%$ nitrogen, $0.2-0.4 \%$ phosphorus and $0.2-0.3 \%$ potassium (Maurya 2012). Sheidrick et al. (2003) showed that the amount of nutrients returned to the field per human feces and urine could reach $1.00 \mathrm{~kg}$ of $\mathrm{N}, 0.25 \mathrm{~kg}$ of $\mathrm{P}$ and $0.25 \mathrm{~kg}$ of $\mathrm{K}$ per year. At the same time, the use of human excreta can also improve soil structure and porosity and increase soil organic carbon. These authors also showed positive effects of human excreta on plant growth. Magwaza et al. (2020) used human excretaderived materials (HEDMs) for hydroponic cultivation of tomato seedlings and found that the physiological performance and leaf nutrient composition of tomato plants were effectively improved. Moya et al. (2019) found that human excreta-based fertilizers increased the yield of French beans by $30 \%$ compared to conventional fertilizers.

With the prevalence of chemical fertilizers and the development of agricultural industrialization, human excreta has gradually been transformed from a resource to a waste product, disrupting the cycle of agriculture and sanitation and exacerbating the negative impact on the ecosystem. At present, basic sanitation facilities can be broadly divided into two types: flush toilets and dry toilets. Human excreta is mixed with flushing water through flush toilets to form black water, which is usually transported to a sewage treatment plant for centralized discharge to meet standards. This process is often accompanied 
by the waste of large amounts of natural fertilizer resources and the consumption of capital and manpower (Shi et al. 2018). In dry toilet systems, the nutrients in human excreta are mostly retained because they are not diluted by water (Butkovskyi et al. 2017). Some farmers separate and collect feces and urine for processing and utilization to maximize resource recovery (Jönsson and Vinnerås 2007). However, the presence of pathogenic bacteria can increase the risk to human and environmental health if feces are not disposed of in a timely and effective manner. Therefore, rational resource utilization of human excreta, including harmless treatment and safe application, to improve nutrient utilization is beneficial to promote farm fertility and improve crop yield for sustainable agricultural development.

An ectopic fermentation bed system (EFS) was developed to overcome the pollution problem of livestock breeding waste (Guo et al. 2013). By adding complex microbial agents to the fermentation system filled with bulking materials, the breeding waste is continuously and dynamically decomposed. This technology is more stable and efficient than ordinary static composting and is less affected by the external environment. Previous studies have confirmed that EFS can effectively treat livestock manure and farm wastewater, and fermented fills can be returned to the field as bioorganic fertilizer, which has good environmental benefits and economic value (Guo et al. 2013; Yang et al. 2019; Chen et al. 2021a). However, the feasibility of EFS to treat human excreta and the fertilization value of decomposed fillers have not yet been reported. Unlike livestock manure, the content of harmful substances such as heavy metals and pesticide residues in human excreta is generally relatively low, and the risk of pathogen transmission is low, thus reducing the ecological safety risk of resource utilization (Penakalapati et al. 2017). Therefore, we hypothesized that decomposed fillers, i.e., degraded human excreta from an EFS, could be used as bioorganic fertilizers to provide sufficient fertility for plant growth and to improve soil quality.

In this study, we used Chinese pakchoi (Brassica chinensis L.) as the research target and initially investigated the effects of EFS fillers treating different types of human excreta on pakchoi growth, quality and nutrients and soil quality at different application rates. The main objectives of this study were (1) to evaluate the fertilizer potential of different products of human excreta fermentation, (2) to screen the filler application rates that would ensure the yield and quality of pakchoi and maintain soil nutrient balance while reducing environmental pollution from fertilizer application, and (3) to reveal the correlation between soil environmental factors and pakchoi yield and quality. The results of this study are of great significance for the recycling of human excreta and the promotion and application of EFSs.

\section{Materials And Methods}

\subsection{Preparation and characteristic analyses of fermentation bed fillers}

The two fermentation bed fillers were obtained by aerobic fermentation of human manure and black water from toilets for 40 days using EFSs. At the beginning of the experiment, corn straw and rice husk were mixed as raw materials at a mass ratio of $1: 1$ and mixed with $200 \mathrm{~g}$ of microbial agent in a 
fermentation box $(45 \mathrm{~cm} \times 45 \mathrm{~cm} \times 45 \mathrm{~cm})$. The test was divided into two treatments, one with human feces added to the EFS and the other with toilet black water added to the EFS stirring well, both with adjustment of the initial moisture content to approximately 50\%. Each treatment was replicated three times. Then, human excreta was added to the fermentation beds every 7 days to maintain the moisture content of the fillers at $50 \unrhd 60 \%$. The fillers were carried out once a day with manual stirring from the bottom to the top of the fermentation boxes for $3 \mathrm{~min}$. The experiment was carried out continuously for 40 days. Finally, the fermentation bed fillers were collected, and their morphological and physical properties, including water content, $\mathrm{pH}$, electrical conductivity (EC), organic matter and $\mathrm{C} / \mathrm{N}$ ratio, were determined with reference to published methods (Guo et al. 2013; Yang et al. 2019; Awasthi et al. 2018). The nutrient composition of the fermentation products was also analyzed.

\subsection{Experimental design}

A pot experiment was conducted at the Institute of Environment and Sustainable Development in Agriculture, Chinese Academy of Agricultural Science. Chinese pakchoi (B. chinensis L.) was implemented as a test plant (from August 8,2021 , to September 25,2021). The soil used in this study was collected from the topsoil $(20 \mathrm{~cm}$ ) of agricultural land in Beijing, China, had a pH of 8.64 and contained $26.1 \%$ organic matter, $76.76 \mathrm{mg} \cdot \mathrm{kg}^{-1}$ available nitrogen, $18.08 \mathrm{mg} \cdot \mathrm{kg}^{-1}$ available phosphorus (AP) and 396.35 $\mathrm{mg} \cdot \mathrm{kg}^{-1}$ available potassium (AK). Experiments were divided into 9 groups, and fermentation bed fillers and soil were mixed as described in Table 1 . Each mixture weighing $1 \mathrm{~kg}$ was added to a plastic pot (20 $\mathrm{cm} \times 16 \mathrm{~cm}$ ). Each treatment was replicated three times, and therefore, there were 27 pots in total in this study. The pots containing soils and fertilizers were submerged for one week, after which Chinese pakchoi seeds were sown. Each pot was covered with approximately $1 \mathrm{~cm}$ of dry soil and watered regularly. The pots were placed completely in the natural environment (temperature: $24-30^{\circ} \mathrm{C}$, humidity: $70-85 \%)$. When the pakchoi grew $2 \bowtie 3$ leaves, the seedlings were thinned to four similar plants in each pot. After growth for 40 days, Chinese pakchoi seedlings were harvested.

Table 1

The parameters of different treatments for fertilizer and soil.

\begin{tabular}{|llllllllll|}
\hline Treatments & CK & HF1 & HF2 & HF3 & HF4 & BW1 & BW2 & BW3 & BW4 \\
\hline $\begin{array}{l}\text { Fermented fillers (human } \\
\text { feces) }\end{array}$ & 0 & $1 \%$ & $2 \%$ & $5 \%$ & $10 \%$ & 0 & 0 & 0 & 0 \\
\hline $\begin{array}{l}\text { Fermented fillers } \\
\text { (Blackwater) }\end{array}$ & 0 & 0 & 0 & 0 & 0 & $1 \%$ & $2 \%$ & $5 \%$ & $10 \%$ \\
\hline soil & $100 \%$ & $99 \%$ & $98 \%$ & $95 \%$ & $90 \%$ & $99 \%$ & $98 \%$ & $95 \%$ & $90 \%$ \\
\hline
\end{tabular}

\subsection{Sampling and analysis}

Plant height was measured with a ruler on days 7, 15, 25 and 40 of pakchoi growth. On the harvest day, whole plant samples were collected. The root soil was washed and dried, root length was measured, and the fresh weight was measured by electronic balance. Subsamples of fresh plant samples were collected and stored in an $80^{\circ} \mathrm{C}$ refrigerator for the determination of soluble protein content, vitamin C (VC) content, 
nitrate content and soluble sugar content according to the method described by Qiu et al. (2013). The soluble protein content was determined by Coomassie brilliant blue colorimetry. The soluble sugar content was determined by anthrone colorimetry. The VC content was determined by the 2,6dichlorophenol-indophenol method. The nitrate content was determined by nitrate-nitrogen colorimetry. The remaining samples were oven-dried at $105^{\circ} \mathrm{C}$ for $30 \mathrm{~min}$ and then at $70^{\circ} \mathrm{C}$ to a constant weight. The dry biomass was weighed. The dried plant samples were then ground into powder and used to determine total nitrogen, phosphorus and potassium by the method of Zhang et al. (2017).

On days 0 and 40 of planting, the soils at five points in each pot were randomly sampled, and the above soils were mixed and considered one sample. The collected soil samples were naturally air-dried, and the residues of plant roots were removed. The air-dried soil samples were ground and sieved through $1 \mathrm{~mm}$ and $0.25 \mathrm{~mm}$ mesh for soil physicochemical property analysis. The soil $\mathrm{pH}$ and EC were determined using a pH meter and EC meter, respectively, in a 1:10 soil-to-water (w/v) suspension. Soil organic matter (SOM) was analyzed using the oil bath- $\mathrm{K}_{2} \mathrm{Cr}_{2} \mathrm{O}_{7}$ titration method (Jia et al. 2020). Soil alkali-hydrolyzed nitrogen (AN), AP and AK were determined by the alkali-hydrolyzed diffusion method, molybdenum blue colorimetric method and flame photometry, respectively (Song 2020; Jia et al. 2020).

\subsection{Statistical analysis}

Statistical analyses in this study were conducted using SPSS v.22. One-way ANOVA combined with Duncan's test was used to determine statistical significance $(p<0.05)$ among treatments. Spearman correlation analysis and redundancy analysis (RDA) were performed by R software (Version 3.6.1). All figures were generated with Origin 2018.

\section{Results And Discussion}

\subsection{Characteristics of fermentation fillers}

Human feces and black water from toilets were fermented in the EFS for 40 days. The basic physicochemical properties of the two fermentation fillers at the end of the experiment are shown in Table 2. Although fermentation bed fillers have the basic properties of organic fertilizers, the possible presence of ammonia, salts, heavy metals, and organic acids in the compost is a major source of phytotoxicity (Gavilanes-Teran et al. 2016), so it is particularly important to evaluate the safety and maturity of the fillers. Filler decay is an important indicator to evaluate the performance of fertilizer, which can be judged by a combination of $\mathrm{pH}, \mathrm{C} / \mathrm{N}$, seed germination index $(\mathrm{Gl})$ and other indicators. It is generally considered that when the $\mathrm{pH}$ of fillers is stable at $8 \otimes 9$, the $\mathrm{C} / \mathrm{N}$ ratio drops below 20 , and the $\mathrm{GI}$ value exceeds $80 \%$, at which point the filler is fully decomposed and not toxic to plants (Wang et al. 2022). According to the indicators in Table 2 , the two fermented fillers basically met the requirements for maturity and may be beneficial to plant growth. However, the EC values of the two fillers were 4.35 $\mathrm{mS} / \mathrm{cm}$ and $4.45 \mathrm{mS} / \mathrm{cm}$. Awasthi et al. (2018) found that EC levels in composts exceeding $3 \mathrm{mS} / \mathrm{cm}$ may negatively affect plant growth. When excessive fillers are applied to the soil, large amounts of soluble salts can lead to a significant reduction in soil water effectiveness, exposing plants to salt stress 
and making seedling establishment difficult. Therefore, the appropriate amount of fertilizer application needs to be further clarified.

The nutrient content of filler is an important indicator to evaluate whether the filler can achieve resource utilization. After a long duration of aerobic fermentation, microorganisms can completely degrade complex organic matter such as lignin and cellulose and accelerate the release of nutrients and elements to fertilizer (Gao et al. 2013). The total nutrient contents $\left(\mathrm{N}+\mathrm{P}_{2} \mathrm{O}_{5}+\mathrm{K}_{2} \mathrm{O}\right)$ of the two fermentation fillers were $9.85 \%$ and $5.85 \%$, meeting the nutritional standard of greater than $5 \%$ total nutrients of organic fertilizers (Ren et al. 2016). This result indicates that the fermented fillers used in this study have high fertility and can be applied in agricultural soils.

Human excreta usually carry pathogenic bacteria and parasites, which can easily cause contamination of soil and crops without proper treatment (Rose et al. 2015). Therefore, the safety of fermentation fillers needs to be tested. The fecal coliform counts of both fillers were significantly lower than $100 \mathrm{MNP} / \mathrm{g}$, and the mortality rate of Ascaris eggs was $100 \%$. Therefore, the fermented fillers have reached safety standards as agricultural organic fertilizers and can be safely utilized.

Table 2

Physicochemical characteristics of fermentation fillers.

\begin{tabular}{|lll|}
\hline Materials & Fermented fillers (human feces) & Fermented fillers (Blackwater) \\
\hline $\mathrm{pH}$ & $8.68 \pm 0.01$ & $7.69 \pm 0.03$ \\
\hline $\mathrm{EC}(\mathrm{mS} / \mathrm{cm})$ & $4.35 \pm 0.03$ & $4.45 \pm 0.06$ \\
\hline $\mathrm{MC}(\%)$ & $40.32 \pm 1.12$ & $46.74 \pm 0.88$ \\
\hline $\mathrm{OM}(\%)$ & $66.99 \pm 2.05$ & $65.11 \pm 1.68$ \\
\hline $\mathrm{TN}(\%)$ & $2.86 \pm 0.11$ & $1.88 \pm 0.06$ \\
\hline $\mathrm{TP}(\%)$ & $2.24 \pm 0.24$ & $1.56 \pm 0.04$ \\
\hline TK $(\%)$ & $1.55 \pm 0.09$ & $0.68 \pm 0.02$ \\
\hline $\mathrm{C} / \mathrm{N}$ & $14.68 \pm 1.47$ & $20.09 \pm 2.05$ \\
\hline GI $(\%)$ & $113.79 \pm 2.20$ & $108.05 \pm 3.13$ \\
\hline Fecal coliform (MNP/g) & 74 & 82 \\
\hline Ascaris egg mortality rates & $100 \%$ & $100 \%$ \\
\hline Bacteria abundance $\left(\mathrm{cfu} \cdot \mathrm{g}^{-1}\right)$ & $3.88 \times 10^{8}$ & $1.27 \times 10^{8}$ \\
\hline
\end{tabular}

\section{Notice}

MC, moisture content; TOC, total organic carbon; TN, total nitrogen; TP, total phosphorous; TK, total potassium; GI, seed germination index. " \pm " display the standard error. 


\subsection{Physiological characteristics of pakchoi under different treatments}

\subsubsection{Biomass and growth status of pakchoi}

Plant height, root length, fresh weight and dry matter accumulation are important indicators reflecting the biomass and growth status of pakchoi, of which plant height is the most intuitive (Doan et al. 2013). As shown in Fig. 1, there was no significant difference in the plant height of pakchoi in each group at the early stage of growth (7 days), indicating that the fillers had no effect on the growth of pakchoi at this time. This result may be related to the slow release of organic nutrients (Chen et al. 2021b). As time passed, the nutrients in the fillers were gradually released, and the pakchoi showed significant differences in plant height as it adapted to the different filler application amounts. On days 15, 25 and 40, the plant height of the HF3 group was always at the highest level and was significantly different from all other groups. At 40 days of harvest, the plant height of pakchoi reached the maximum. Compared with the control (CK) group, the plant height of filler groups increased by $4.00 \varangle 42.43 \%$, among which HF3 was the highest $(16.38 \mathrm{~cm})$. The results showed that the large amount of nutrients such as $\mathrm{N}, \mathrm{P}$ and $\mathrm{K}$ in the fillers increased the effective nutrients of the soil, thus promoting the growth of pakchoi.

The root length and yield of pakchoi at harvest showed similar results to plant height (Table 3). Compared to the CK group, the application of fermentation bed fillers during planting was effective in promoting root growth and increasing the yield of pakchoi. The root length of pakchoi in the filler treatment group was $0.32 \varangle 1.56 \mathrm{~cm}$ longer than that in the CK group. This indirectly reflected that fermentation bed fillers could enhance the ability of crops to absorb water and nutrients to a certain extent. The yield of pakchoi in the HF and BW groups was significantly higher than that in the CK group, with fresh weight increasing by $3.60 \otimes 29.32 \mathrm{~g} \cdot$ pot $^{-1}$ and dry weight increasing by $0.16 \otimes 2.84 \mathrm{~g} \cdot$ pot $^{-1}$. Compared with the BW group, the HF group had a higher plant height and yield under the same amount of application. This difference could be attributed to the fact that the nutrients in the feces were not diluted and were retained more in the fillers. Except for the HF4 group, the yield of pakchoi increased with increasing filler amount. This suggests that filler application may negatively affect the yield of pakchoi above a certain amount. The higher fecal content in the HF group than in the BW group and the higher $\mathrm{pH}$ and $\mathrm{EC}$ of the fillers resulted in relatively high ionic toxicity to the plants. Nutrient growth parameters have been shown to be negatively correlated with elevated salinity (Molazem and Bashirzadeh 2014). The growth of pakchoi was slowed by salt stress, and an early decline in growth was even observed; this inhibitory effect has been reported in many plants (Liu et al. 2018; Song et al. 2020). In summary, the application of $5 \%$ human fecal fermentation fillers was the most effective among all treatments in increasing the biomass of pakchoi. 
Table 3

Effect of different treatments on pakchoi growth.

\begin{tabular}{|llll|}
\hline Treatments & Root length $(\mathbf{c m})$ & Fresh weight $\left({\left.\mathbf{g} \cdot \mathbf{p o t}^{-1}\right)}^{\mathbf{1}}\right)$ & Dry weight $\left({\left.\mathbf{g} \cdot \mathbf{p o t}^{-1}\right)}^{-1}\right)$ \\
\hline CK & $4.33 \pm 0.05^{\mathrm{c}}$ & $16.20 \pm 0.57^{\mathrm{g}}$ & $0.68 \pm 0.05^{\mathrm{g}}$ \\
\hline HF1 & $5.20 \pm 0.11^{\mathrm{b}}$ & $20.52 \pm 1.04^{\mathrm{e}}$ & $1.24 \pm 0.15^{\mathrm{e}}$ \\
\hline HF2 & $5.24 \pm 0.19^{\mathrm{b}}$ & $29.48 \pm 2.29^{\mathrm{c}}$ & $2.24 \pm 0.23^{\mathrm{d}}$ \\
\hline HF3 & $5.89 \pm 0.28^{\mathrm{a}}$ & $45.52 \pm 1.15^{\mathrm{a}}$ & $3.52 \pm 0.26^{\mathrm{a}}$ \\
\hline BW1 & $5.88 \pm 0.20^{\mathrm{a}}$ & $39.52 \pm 0.80^{\mathrm{b}}$ & $3.00 \pm 0.12^{\mathrm{b}}$ \\
\hline BW2 & $4.65 \pm 0.17^{\mathrm{c}}$ & $18.12 \pm 1.56^{\mathrm{f}}$ & $0.84 \pm 0.03^{\mathrm{fg}}$ \\
\hline BW3 & $5.04 \pm 0.12^{\mathrm{b}}$ & $19.8 \pm 0.63^{\mathrm{e}}$ & $1.12 \pm 0.11^{\mathrm{ef}}$ \\
\hline BW4 & $5.26 \pm 0.28^{\mathrm{b}}$ & $22.72 \pm 2.11^{\mathrm{d}}$ & $1.44 \pm 0.28^{\mathrm{e}}$ \\
\hline
\end{tabular}

\section{Notice}

The data are presented as the mean \pm standard deviation (SD). Different letters in the same column mean significant difference at 0.05 level.

\subsubsection{Quality}

The soluble sugar, VC, soluble protein and nitrate contents responded to the quality status of pakchoi. The contents of soluble protein and VC in pakchoi were significantly increased by each packing treatment compared to those in CK plants (Fig. 2a-b). Under the same dosage, the HF group was more effective in enhancing the soluble protein of pakchoi than the BW group, which had a better improvement effect on VC. This diversity may be caused by the different properties of feces and black water (Jönsson 2007; Rose et al. 2015). The soluble protein content of pakchoi in the HF and BW groups increased with increasing filler addition, which increased $11.95 \bigotimes 146.90 \%$ compared to CK. This result may be due to the relatively high filler content and the high protease activity, which in turn promoted the synthesis of proteins in pakchoi. The VC content of pakchoi under different fertilization conditions increased to different degrees relative to the CK group, with increases reaching 0.24-1.23-fold, with the highest VC content of $0.167 \mathrm{mg} / \mathrm{g}$ observed under the BW4 treatment. The VC content of pakchoi in HF4 was $7.83 \%$ lower than that in HF3, which was related to the excess nitrogen in HF4. It was shown that excessive application of nitrogen fertilizer reduced the amount of carbohydrates such as D-mannose and Lgalactose, the precursors of VC synthesis (Mellidou et al. 2021), thus affecting the synthesis and accumulation of VC. Similar findings were obtained by Shi et al. (2021). 
Soluble sugars, as important osmotic substances in plants, play an important role in the plant stress response (Campbell et al. 1983). With increasing filler application, the soluble sugar content of pakchoi showed a gradual decrease in the HF group, while it first increased and then decreased in the BW group (Fig. 2c). The results showed that neither too low nor too high filler content was conducive to the synthesis compared with the CK group, and only the soluble sugar content of pakchoi increased in HF1 and HF2, with the highest content in HF1, which was 1.26ه4.31 times higher than in the other groups. However, the soluble sugar content in HF4, BW3 and BW4 was the lowest, which may be because high doses of organic fertilizers reduced the activity of sugar-metabolizing enzymes under the effect of fermentation and decomposition (Zhu et al. 2018), thus inhibiting the synthesis of soluble sugars. As shown in Fig. 2d, the nitrate content of pakchoi was proportional to the amount of filler applied. Previous studies found a positive correlation between nitrate content and nitrogen content in pakchoi (Jia et al. 2020), which was also confirmed in this study. The HF4 group had the most significant effect on the nitrate content of pakchoi, which was $1.80 \otimes 5.48$ times higher than that of the other groups. The nitrate content was lower than the Chinese limit for nitrate in vegetables $(432 \mathrm{mg} / \mathrm{kg})$, but there was still a risk of mild nitrate contamination. The high application of fillers increases the nitrogen content in the soil while causing excess nitrate uptake by vegetables, accompanied by a large consumption of energy and soluble sugar content. Nitrate accumulation is harmless to the plant itself, but it is a great threat to human health (Santamaria 2006). Therefore, the best quality of pakchoi was obtained in the HF3 and BW4 groups without affecting the yield of pakchoi.

\subsubsection{Nutrient uptake}

Deficiencies in any of the elements of nitrogen, phosphorus and potassium will result in abnormal plant growth and reduced yield. After harvest, the accumulation of N, P and K in the body of pakchoi was increased to varying degrees compared to that in CK group plants (Fig. 3). This result indicates that the nutrient accumulation of pakchoi can be promoted by the application of fillers. The TK content and TN content in plants were similar, and both were significantly higher than the TP content, consistent with the results of Kelova et al. (2021). These results indicate a greater demand for nitrogen and potassium than phosphorus in pakchoi and are crucial elements required for plant growth. Moreover, potassium can significantly increase the uptake and utilization of nitrogen by plants and can be quickly converted into protein (Hou et al. 2019). Nutrient uptake varied significantly among treatments, reflecting differences in biomass. Among all treatments, the TN content in HF4 and BW4 was significantly higher than that in the other groups, reaching $5.21 \%$ and $4.51 \%$, respectively. The TP and TK contents in HF3 were the highest, $0.44 \%$ and $1.08 \%$ higher than in the CK group, respectively. Different types and application rates of

organic fertilizers had different effects on plant nutrient accumulation. Zai et al. (2010) found that the accumulation of $\mathrm{N}, \mathrm{P}$ and $\mathrm{K}$ in wheat increased with increasing application rate within a certain range of when applying chicken manure. The accumulation of N, $\mathrm{P}$ and $\mathrm{K}$ in the BW group increased with increasing application rate, while the TP and TK contents in the HF group increased first and then decreased. This result may be because excessive application of fertilizer tends to produce fertilizer damage, which is detrimental to plant growth and thus inhibits nutrient uptake in pakchoi. 


\subsection{Changes in soil properties before and after planting under different treatments}

\subsection{1 $\mathrm{pH}$ and EC}

Soil $\mathrm{pH}$ and EC values collected before and after planting are shown in Fig. 4. The pH of the soil and amended soil ranged from 8.0凶9.0, with the $\mathrm{pH}$ of the $\mathrm{HF}$ treatment being slightly lower than that of the BW treatment (Fig. 4a). Soil pH can affect the ionic form of several elements in the soil and the efficiencies of denitrification and nutrients (Wang et al. 2020). The soil pH decreased more as the filler addition percentage increased. This phenomenon may arise due to the presence of acidic substances in the fillers themselves and the decomposition of organic matter during the transformation process to produce organic acids (Chen et al. 2021a). After 40 days of the planting process, the soil pH showed a significant difference, which was mainly due to the buffering effect of fillers after application to the soil. Except for CK, HF1, HF2 and BW2, the other treatments showed an increasing trend in pH, with BW4 showing the largest increase. The large amount of organic matter contained in the fillers produced water, nitrate, sulfate and $\mathrm{OH}^{-}$after mineralization and decomposition in the soil, which led to an increase in soil $\mathrm{pH}$. Numerous studies have also shown that the application of organic fertilizers can improve the physicochemical properties of soil, increase the acid-base buffer capacity of soil, effectively inhibit the acidification process, and improve soil production levels (Song et al. 2020; Shi et al. 2021). However, the addition of low-dose fermentation bed fillers did not provide a certain effective buffering effect on soil acidity and alkalinity.

Soil EC reflects the salinity of the soil and its suitability for plant growth. As shown in Fig. 4b, the application of fillers increases soil EC, which increases significantly when added at more than $5 \%$. The reason for this phenomenon is that human excreta contains a large amount of salt ions, especially in urine (Rose et al. 2015). This also explains why the EC values of the BW treatment are slightly higher than those of the HF treatment. However, a high salt content can damage the soil agglomerate structure and thus cause poor plant growth, so overfertilization should be avoided. Except for in the CK group, the EC of the soil containing with fillers decreased after planting, with the decrease ranging from $6.70-59.37 \%$, with that in the HF4 group showing the largest decrease. It was found that soil EC showed a strong negative correlation with pH (Lv et al. 2020), which was consistent with the results of this experiment. From the change in soil EC, the application of fermentation bed fillers can activate the soil metabolic capacity and has a certain effect on improving the soil nature. This result is consistent with those of previous studies on the application of sludge compost to improve soil (Elsalam et al. 2021). Bioorganic fertilizer can reduce the accumulation of salts in the soil and inhibit soil salinization by increasing the proportion of soil aggregates (Lin et al. 2021). Although the high dose of filler addition in this study increased the initial soil salinity, the large amount of organic matter in the fillers enhanced the metabolic capacity of the soil and alleviated the soil salinization to some extent.

\subsubsection{SOM}


Crop straw and livestock manure are the main sources of organic matter in agricultural soils, and the application of these organic fertilizers not only protects the environment but also improves the efficiency of resource utilization (N'Dayegamiye, et al. 2005; Al-Suhaibani, et al. 2021). The SOM content increased significantly after the application of fillers compared with that in the CK group and was proportional to the amount applied (Fig. 5a). This result is related to the large amount of organic matter contained in the fillers, which also increased the activity of soil microorganisms and promoted the process of organic matter synthesis. With the growth of pakchoi, the organic matter underwent decomposition and metabolism under the action of microorganisms, which, together with the carbon required for crop growth, led to changes in SOM content. Yang et al. (2019) also indicated that the application of fillers could provide a large number of attachment sites for microorganisms and play a stabilizing role in the mineralization and decomposition of organic matter. After harvesting of pakchoi, the SOM content increased by $5.63 \llbracket 23.33 \%$ in the CK and low-application-rate treatments (HF1, HF2, BW1, and BW2), with

the greatest increase in the CK group. In contrast, the SOM content decreased in the high-application-rate treatments (HF3, HF4, BW3 and BW4) by $8.87817 .10 \%$, and the changes in SOM responded to the growth conditions of pakchoi. Overall, in terms of fertilizer application, the higher the application rate was, the higher the SOM content; in terms of filler type, HF was more favorable for increasing the SOM content than BW.

\subsubsection{Available nutrient content}

The amount of soil N, P and K can be important indicators of soil fertility, especially the available nutrients that can be directly absorbed and utilized by plants (Bhavya et al. 2018). In all treatments, HF and BW increased the preplant soil AN, AP and AK contents (Fig. 5b-d). The differences in available nutrient contents between treatments may be caused by the different filler addition ratios of AN, AP and AK inputs. The AN, AP and AK contents of the soil changed after planting, with most of the AN and AP contents increasing and AK content decreasing. This observation indicates that the application of fillers can increase the availability of soil nutrients, but the changes in AK content were not consistent with those reported by Liu et al. (2018). This discrepancy can be explained by the growth depletion of pakchoi and potassium fixation. Therefore, potassium deficiency should be noted when fermentation bed fillers are applied as organic fertilizer and can be appropriately supplemented with potassium fertilizer. The difference in AN content between the HF and BW treatments at the same application rate was not significant but was significantly higher than that of the CK. The highest AP and AK contents were found in the HF4 treatment at $154.39 \mathrm{mg} \cdot \mathrm{kg}^{-1}$ and $1015.88 \mathrm{mg} \cdot \mathrm{kg}^{-1}$, respectively, which were significantly different from those of the other groups. It was found that excessive application of organic fertilizers caused $\mathrm{N}, \mathrm{P}$, and $\mathrm{K}$ enrichment in the soil, which increased the risk of environmental pollution through surface runoff and rainwater flushing (Zhan et al. 2016). On the other hand, excessive nutrients are not fully absorbed and utilized by plants but can have negative or even toxic effects on their growth (Zhao et al. 2019). Therefore, reasonable control of organic fertilizer application is the key to ensuring crop yield and ecological safety. 


\subsection{Relationships between soil properties and physiological characteristics of pakchoi}

To better understand the relationships among plant growth traits, biomass, quality, nutrients, and soil properties, we analyzed their associations using Spearman correlation analysis and revealed potential factors affecting yield and quality (Fig. 6a). The biomass of pakchoi was significantly and positively correlated with plant height, root length, TN, TK and soil nutrient contents. Meng et al. (2018) found that relatively long and large rice root systems contributed to relatively high biomass and seed yield. Nutrient accumulation in plants and the fertility of the environment they are in have also been shown to have a direct effect on plant growth and yield improvement (Jia et al. 2020; Magwaza et al. 2020). The nitrate content of pakchoi had a strong positive correlation with TN, SOM and soil available nutrients, while the soluble sugars of pakchoi were negatively correlated with soil AN and AK. Fertilizer application increases the nitrogen content in the soil while causing excess uptake by plants, which results in nitrate accumulation (Barhoumi 2017). In addition, plants consume a large amount of energy in the process of absorbing nutrients, which decreases the soluble sugar content. The correlations between soluble protein of pakchoi and its growth traits, biomass and soil properties were significant, which was also suggested by Qu et al. (2020). It is evident that soil properties are the main driving factors affecting plant yield and quality.

Further analysis of soil physicochemical factors and physiological characteristics of pakchoi was performed using RDA (Fig. $6 \mathrm{~b}$ ). A total of $97.83 \%$ and $0.26 \%$ of the physiological characteristics of pakchoi were explained by RDA1 and RDA2 for each treatment, respectively. In other words, all soil physicochemical factors cumulatively explained $98.09 \%$ of the physiological characteristics of pakchoi. The effects of soil AN, AP, AK and SOM on the growth and quality of pakchoi were similar, and the vector arrows were less angled, which was attributed to the fact that C, N, P and K are the essential and most demanded nutrients for plant growth, and they synergistically promote plant growth and improve yield. Soil EC had the strongest correlation with the physiological characteristics of pakchoi, while soil pH was weaker. Some studies have shown that soil pH is a key factor affecting nutrient uptake and the growth of plants, but this phenomenon was not reflected in this study. This may be due to the small difference in soil $\mathrm{pH}$ between different treatments and the suitable range for plant growth; therefore, it did not have a significant effect on the growth of pakchoi (Ren et al. 2018; Shi et al. 2021). We believe that these results can help to improve crop yield and quality. However, this study is only a preliminary pot experiment, and larger field trials are needed to determine the long-term effects of applying fermentation bed fillers.

\section{Conclusion}

In this study, we evaluated the fertilization value of decomposed fills obtained from different types of human excreta treated with ectopic fermentation bed technology. The results showed that all treatments promoted the growth of pakchoi and improved the soil quality to some extent. Since HF was richer in more nutrients, such as $\mathrm{N}, \mathrm{P}$ and $\mathrm{K}$, than $\mathrm{BW}$, its promotion effect on the growth and development of 
pakchoi was more obvious. However, with the increase in added amount, there was a risk of excessive nitrate in vegetables and enrichment of soil nutrients. Moreover, soil properties and nutrient contents are important factors affecting plant yield and quality. To improve the yield and quality of crops while reducing the risk of soil safety, the amount of filler application should be reasonably controlled, with HF not exceeding $5 \%$ and BW not exceeding $10 \%$. However, this study was limited to exploring only the effect of a single application of filler organic fertilizer, and subsequent application with inorganic fertilizer should be realized to ensure efficient utilization in practical production.

\section{Declarations}

Authors Contribution Jiabin Li: Carried out and performed the experiment, processed and analyzed data, visualization, wrote the manuscript. Bing Geng, Changxiong Zhu, Xue Liu and Liangguo Luo: Conceived and designed the experiments, fund support, helped perform the analysis with constructive discussions, determined the manuscript. Zhuobo Chen, Shan Jin: helped to determine of physical and chemical properties. All authors read and approved the final manuscript.

Funding This work is financially supported by the National Water Pollution Control and Treatment Science and Technology Major Project in China (2017ZX07603002).

Data Availability The datasets used or analyzed during the current study are available from the corresponding author on reasonable request.

Ethical Approval The work was based on environmental samples from rural areas of China, mainly from household toilets, all samples were taken from rural septic tanks or dry toilets, belonging to environmental samples. There are no ethical issues, therefore, Ethics approval is not required for this paper.

Consent to Participate Not applicable

Consent to Publish Not applicable

Competing Interests The authors declare that they have no known competing financial interests or personal relationships that could have appeared to influence the work reported in this paper.

\section{References}

1. Al-Suhaibani N, Selim M, Alderfasi A, El-Hendawy S (2021) Integrated Application of Composted Agricultural Wastes, Chemical Fertilizers and Biofertilizers as an Avenue to Promote Growth, Yield and Quality of Maize in an Arid Agro-Ecosystem. Sustainability 13:7439. https://doi.org/ $10.3390 /$ su 13137439

2. Avvannavar SM, Mani M, WHO (2007) Guidelines for the safe use of wastewater, excreta and greywater, Volume 3: Wastewater and Excreta use in Aquaculture, 2006, 20, Avenue Appia, 1211, 
Geneva, 27 Switzerland, 92-4-154684-0 (V 3), US \$ 45.00, 158. Sci. Total Environ 382(2):391-392. https://doi.org/10.1016/j.scitotenv.2007.04.034

3. Awasthi MK, Wang Q, Awasthi SK, Wang M, Chen H, Ren X, Zhao J, Zhang Z (2018) Influence of medical stone amendment on gaseous emissions, microbial biomass and abundance of ammonia oxidizing bacteria genes during biosolids composting. Bioresour Technol 247:970-979. https://doi.org/10.1016/j.biortech.2017.09.201

4. Barhoumi Z (2017) Insights Into the Growth Response and Nitrogen Accumulation and Use Efficiency of the Poaceae Grass Brachypodium distachyon to High Nitrogen Availability. Russ J Plant Physl + 64 6839-844. https://doi.org/10.1134/S1021443717060024

5. Bhavya G, Chandra Shaker K, Jayasree G, Reddy MM (2018) Effect of integrated use of phosphorus, biofertilizers and organic manures on soil available nutrient status and yield of greengram (Vigna radiata L.). Asian J Soil Sci 13(1):45-49. https://doi.org/10.15740/HAS/AJSS

6. Butkovskyi A, Leal LH, Zeeman G, Rijnaarts HHM (2017) Micropollutants in source separated wastewater streams and recovered resources of source separated sanitation. Environ Res 156:434442. https://doi.org/10.1016/j.envres.2017.03.044

7. Campbell CA, Davidson HR, Mccaig TN (1983) Disposiion of nitrogen and soluble sugars in Manitou spring wheat as influenced by $\mathrm{N}$ fertilizer, temperature and duration and stage of moisture stress. Can J Plant Sci 63:73-90. https://doi.org/10.4141/cjps83-008

8. Chen Q, Wang J, Zhang H, Shi H, Liu G, Che J, Liu B (2021a) Microbial community and function in nitrogen transformation of ectopic fermentation bed system for pig manure composting. Bioresour Technol 319:124155. https://doi.org/10.1016/j.biortech.2020.124155

9. Chen Y, Li X, Li S, Xu Y (2021b) Novel-integrated process for production of bio-organic fertilizer via swine manure composting. Environ Eng Res 26(2):190522. https://doi.org/10.4491/eer.2019.522

10. Doan TT, Ngo PT, Rumpel C, Nguyen BV, Jouquet P (2013) Interactions between compost, vermicompost and earthwormsinfluence plant growth and yield: A one-year greenhouse experiment. Sci Hortic 160:148-154. https://doi.org/10.1016/j.scienta.2013.05.042

11. Elsalam HEA, El-Sharnouby ME, Mohamed AE, Raafat BM, El-Gamal EH (2021) Effect of Sewage Sludge Compost Usage on Corn and Faba Bean Growth, Carbon and Nitrogen Forms in Plants and Soil. Agronomy 11:628. https://doi.org/10.3390/agronomy11040628

12. Gavilanes-Teran I, Jara-Samaniego J, Idrovo-Novillo J, Bustamante MA, Moral R, Paredes C (2016) Windrow composting as horticultural waste management strategy - a case study in Ecuador. Waste Manag 48:127-134. https://doi.org/10.1016/j.wasman.2015.11.026

13. Guo H, Geng B, Liu X, Ye J, Zhao Y, Zhu C, Yuan H (2013) Characterization of bacterial consortium and its application in an ectopic fermentation system. Bioresour Technol 139:28-33. https://doi.org/10.1016/j.biortech.2013.04.029

14. Hou W, Tränkner M, Lu J, Yan J, Huang S, Ren T, Cong R, Li X (2019) Interactive effects of nitrogen and potassium on photosynthesis and photosynthetic nitrogen allocation of rice leaves. BMC Plant Biol 19(1):302. https://doi.org/10.1186/s12870-019-1894-8 
15. Jönsson H, Vinnerås $B$ (2007) Experiences and suggestions for collection systems for sourceseparated urine and faeces. Water Sci Technol 56(5):71-76. https://doi.org/10.2166/wst.2007.558

16. Jia Y, Liao Z, Chew H, Wang L, Lin B, Chen C, Lu G, Lin Z (2020) Effect of Pennisetum giganteum z.x.lin mixed nitrogen-fixing bacterial fertilizer on the growth, quality, soil fertility and bacterial community of pakchoi (Brassica chinensis L.). PLoS ONE 15(2):0228709. https://doi.org/10.1371/journal.pone.0228709

17. Kelova ME, Eich-Greatorex S, Krogstad T (2021) Human excreta as a resource in agriculture Evaluating the fertilizer potential of different composting and fermentation-derived products. Resour Conserv Recycl 175:105748. https://doi.org/10.1016/j.resconrec.2021.105748

18. Liu D, Xie B, Chen D, Liu G, Hu D, Qin Y, Li H, Liu H (2018) Effect of fertilizer prepared from human feces and straw on germination, growth and development of wheat. Acta Astronaut 145:76-82. https://doi.org/10.1016/j.actaastro.2018.01.014

19. Lv H, Zhao Y, Wang Y, Wan L, Wang J, Butterbach-Bahl K, Lin S (2020) Conventional flooding irrigation and over fertilization drives soil pH decrease not only in the top- but also in subsoil layers in solar greenhouse vegetable production systems. Geoderma 363:114156. https://doi.org/10.1016/j.geoderma.2019.114156

20. Magwaza ST, Magwaza LS, Odindo AO, Mditshwa A, Mditshwa C (2020) Evaluating the feasibility of human excreta-derived material for the production of hydroponically grown tomato plants - Part II: Growth and yield. Agric Water Manag 234:106115. https://doi.org/10.1016/j.agwat.2020.106115

21. Maurya NS (2012) Is human excreta a waste? Int J Environmental Technology and Management 15(3-6):325-332. https://doi.org/10.1504/IJETM.2012.049231

22. Mellidou I, Koukounaras A, Kostas S, Patelou E, Kanellis AK (2021) Regulation of Vitamin C Accumulation for Improved Tomato Fruit Quality and Alleviation of Abiotic Stress. Genes 12:694. https://doi.org/10.3390/genes12050694

23. Meng T, Wei H, Li X, Dai Q, Huo Z (2018) A better root morpho-physiology after heading contributing to yield superiority of japonica/indica hybrid rice. Field Crop Res 228:135-146. https://doi.org/10.1016/j.fcr.2018.08.024

24. Molazem D, Bashirzadeh A (2014) Effects of salicylic acid and salinity on growth of maize plant (Zea mays L.). Int J Biosci 4(9):76-82. http://dx.doi.org/10.12692/ijb/4.9.76-82

25. Moya B, Parker A, Sakrabani R (2019) Challenges to the use of fertilisers derived from human excreta: The case of vegetable exports from Kenya to Europe and influence of certification systems. Food Policy 85:72-78. https://doi.org/10.1016/j.foodpol.2019.05.001

26. N'Dayegamiye A, Drapeau A, Laverdière MR (2005) Effets des apports de composts de résidus ménagers sur les rendements des cultures et certaines propriétés du sol. Agrosol 16(2):135-144

27. Penakalapati G, Swarthout J, Delahoy MJ, McAliley L, Wodnik B, Levy K, Freeman MC (2017) Exposure to Animal Feces and Human Health: A Systematic Review and Proposed Research Priorities. Environ Sci Technol 51(20):11537-11552. https://doi.org/10.1021/acs.est.7b02811 
28. Qiu X, Wang Y, Hu G, Wang Q, Zhang X, Dong Y (2013) Effect of different fertilization modes on physiological characteristics, yield and quality of Chinese cabbage. J Plant Nutr 36:948-962. https://doi.org/10.1080/01904167.2012.759972

29. Qu F, Zhang J, Ma X, Wang J, Gao Z, Hu X (2020) Effects of different N, P, K and Ca levels on tomato yield, quality and fertiliser use efficiency. Plant Soil Environ 66:569-575. https://doi.org/10.17221/498/2020-PSE

30. Ren B, Hu Y, Chen B, Zhang Y, Thiele J, Shi R, Liu M, Bu R (2018) Soil pH and plant diversity shape soil bacterial community structure in the active layer across the latitudinal gradients in continuous permafrost region of Northeastern China. Sci Rep 8(1):1-10. https://doi.org/10.1038/s41598-01824040-8

31. Ren G, Xu X, Qu J, Zhu L, Wang T (2016) Evaluation of microbial population dynamics in the cocomposting of cow manure and rice straw using high throughput sequencing analysis. World $\mathrm{J}$ Microbiol Biotechnol 32(2):1-11. https://doi.org/10.1007/s11274-016-2059-7

32. Rose C, Parker A, Jefferson B, Cartmell E (2015) The characterization of feces and urine: a review of the literature to inform advanced treatment technology. Crit Rev Environ Sci Technol 45(17):18271879. https://doi.org/10.1080/10643389.2014.1000761

33. Santamaria $P(2006)$ Nitrate in vegetables: toxicity, content, intake and EC regulation. J Sci Food Agr 86(1):10-17. https://doi.org/10.1002/jsfa.2351

34. Sheldrick WF, Syers JK, Lingard J (2003) Soil nutrient audits for China to estimate nutrien balances and output/input relationships. Agr Ecosyst Environ 94(3):341-354. https://doi.org/10.1016/S01678809(02)00038-5

35. Shi Y, Zhou L, Xu Y, Zhou H, Shi L (2018) Life cycle cost and environmental assessment for resourceoriented toilet systems. J Clean Prod 196:1188-1197. https://doi.org/10.1016/j.jclepro.2018.06.129

36. Shi L, Zheng W, Lei T, Liu X, Hui M (2021) The Effect of Different Soil Amendments on Soil Properties and on the Morphological and Physiological Characteristics of Chinese Cabbage. J Soil Sci Plant Nut 21:1500-1510. https://doi.org/10.1007/s42729-021-00456-6

37. Song D, Chen L, Zhang S, Zheng Q, Ullah S, Zhou W, Wang X (2020) Combined biochar and nitrogen fertilizer change soil enzyme and microbial activities in a 2-year field trial. Eur J Soil Biol 99:103212. https://doi.org/10.1016/j.ejsobi.2020.103212

38. Wang J, Tu X, Zhang H, Cui J, Ni K, Chen J, Cheng Y, Zhang J, Chang S (2020) Effects of ammoniumbased nitrogen addition on soil nitrification and nitrogen gas emissions depend on fertilizer-induced changes in $\mathrm{pH}$ in a tea plantation soil. Sci Total Environ 747:141340. https://doi.org/10.1016/j.scitotenv.2020.141340

39. Wang G, Yang Y, Kong Y, Ma R, Yuan J, Li G (2022) Key factors affecting seed germination in phytotoxicity tests during sheep manure composting with carbon additives. J Hazard Mater 421:126809. https://doi.org/10.1016/j.jhazmat.2021.126809

40. Yang X, Song Z, Zhou S, Guo H, Geng B, Peng X, Zhao G, Xie Y (2019) Insights into functional microbial succession during nitrogen transformation in an ectopic fermentation system. Bioresour 
Technol 284:266-275. https://doi.org/10.1016/j.biortech.2019.03.135

41. Zai AKE, Horiuchi T, Matsui T, Meherunnesa D (2010) Residual Effects of Compost and Green Manure of Pea with Other Organic Wastes on Nutrient-Use Efficiency of Successive Rice after Wheat. Commun Soil Sci Plan 41:2154-2169. https://doi.org/10.1080/00103624.2010.504797

42. Zhan A, Zou C, Ye Y, Liu Z, Cui Z, Chen X (2016) Estimating onfarm wheat yield response to potassium and potassium uptake requirement in China. Field Crop Res 191:13-19. https://doi.org/10.1016/j.fcr.2016.04.001

43. Zhao Q, Guo J, Shu M, Wang P, Hu S (2019) Impacts of drought and nitrogen enrichment on leaf nutrient resorption and root nutrient allocation in four Tibetan plant species. Sci Total Environ 723:138106. https://doi.org/10.1016/j.scitotenv.2020.138106

44. Zhang N, Pan R, Shen Y, Yuan J, Wang L, Luo X, Raza W, Ling N, Huang Q, Shen Q (2017) Development of a novel bio-organic fertilizer for plant growth promotion and suppression of rhizome rot in ginger. Biol Control 114:97-105. https://doi.org/10.1016/j.biocontrol.2017.08.001

45. Zhu J, Qi J, Fang Y, Xiao X, Li J, Lan J, Tang C (2018) Characterization of Sugar Contents and Sucrose Metabolizing Enzymes in Developing Leaves of Hevea brasiliensis. Front Plant Sci 9:58. https://doi.org/10.3389/fpls.2018.00058

46. Zhu L, Jia X, Li M, Wang Y, Zhang J, Hou J, Wang X (2021) Associative effectiveness of bio-organic fertilizer and soil conditioners derived from the fermentation of food waste applied to greenhouse saline soil in Shan Dong Province, China. Appl Soil Ecol 167:104006. https://doi.org/10.1016/j.apsoil.2021.104006

\section{Figures}






Figure 1

Effects of different treatments on plant height of pakchoi. These data were measured on the 7th day, 15 th day, 25 st day and 40 st day after planting. Mean values and standard deviations are shown $(n=3)$. Different letters above bars indicate significant difference at $p<0.05$, based on Duncan's multiple range test. 
(a)

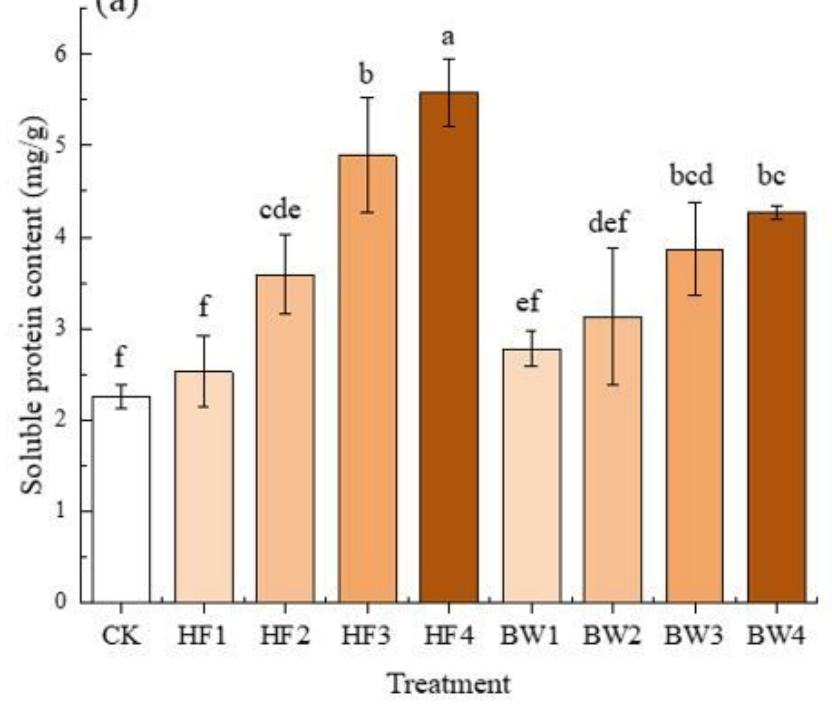

(c)

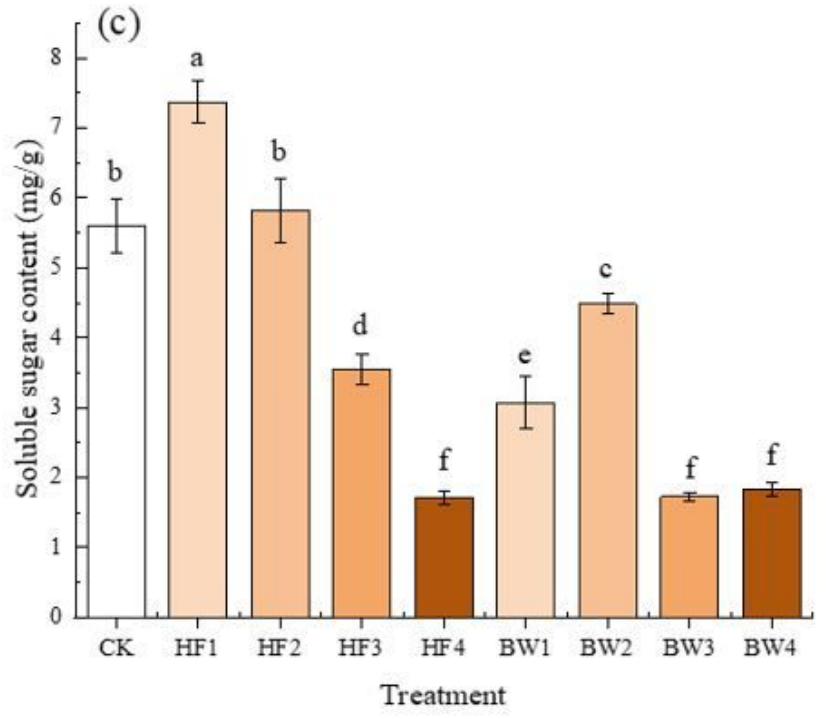

(b)

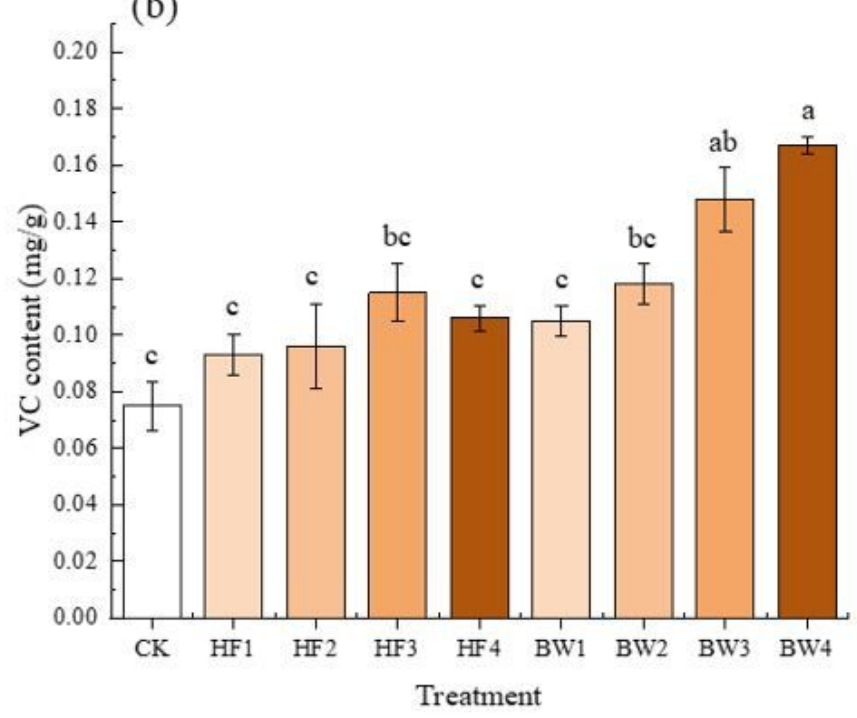

(d)

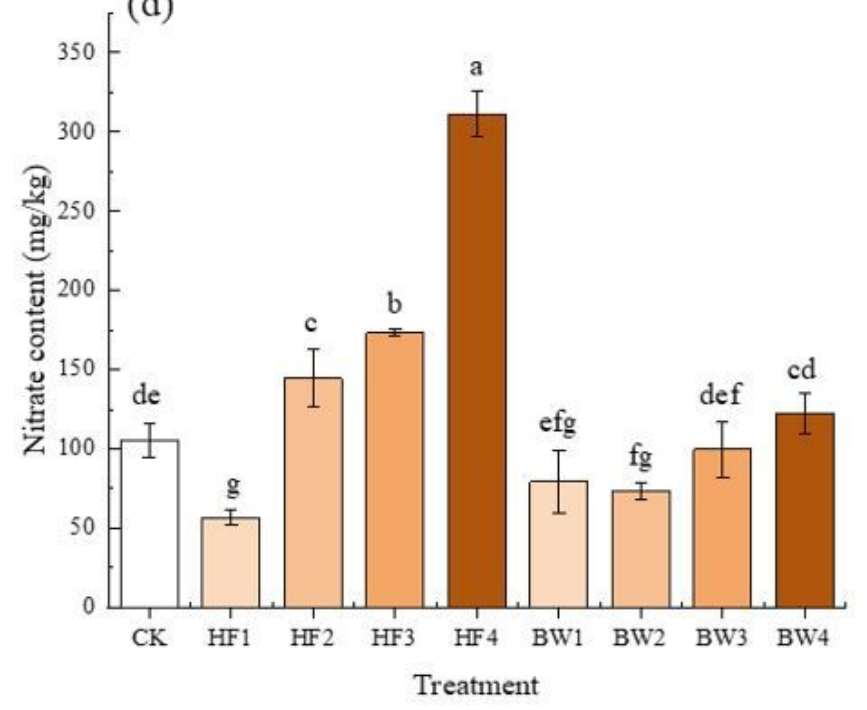

Figure 2

Effect of different treatments on pakchoi quality: (a) soluble protein content; (b) VC content; (c) soluble sugar content; $(d)$ nitrate content. Mean values and standard deviations are shown $(n=3)$. Different letters above bars indicate significant difference at $p<0.05$, based on Duncan's multiple range test. 

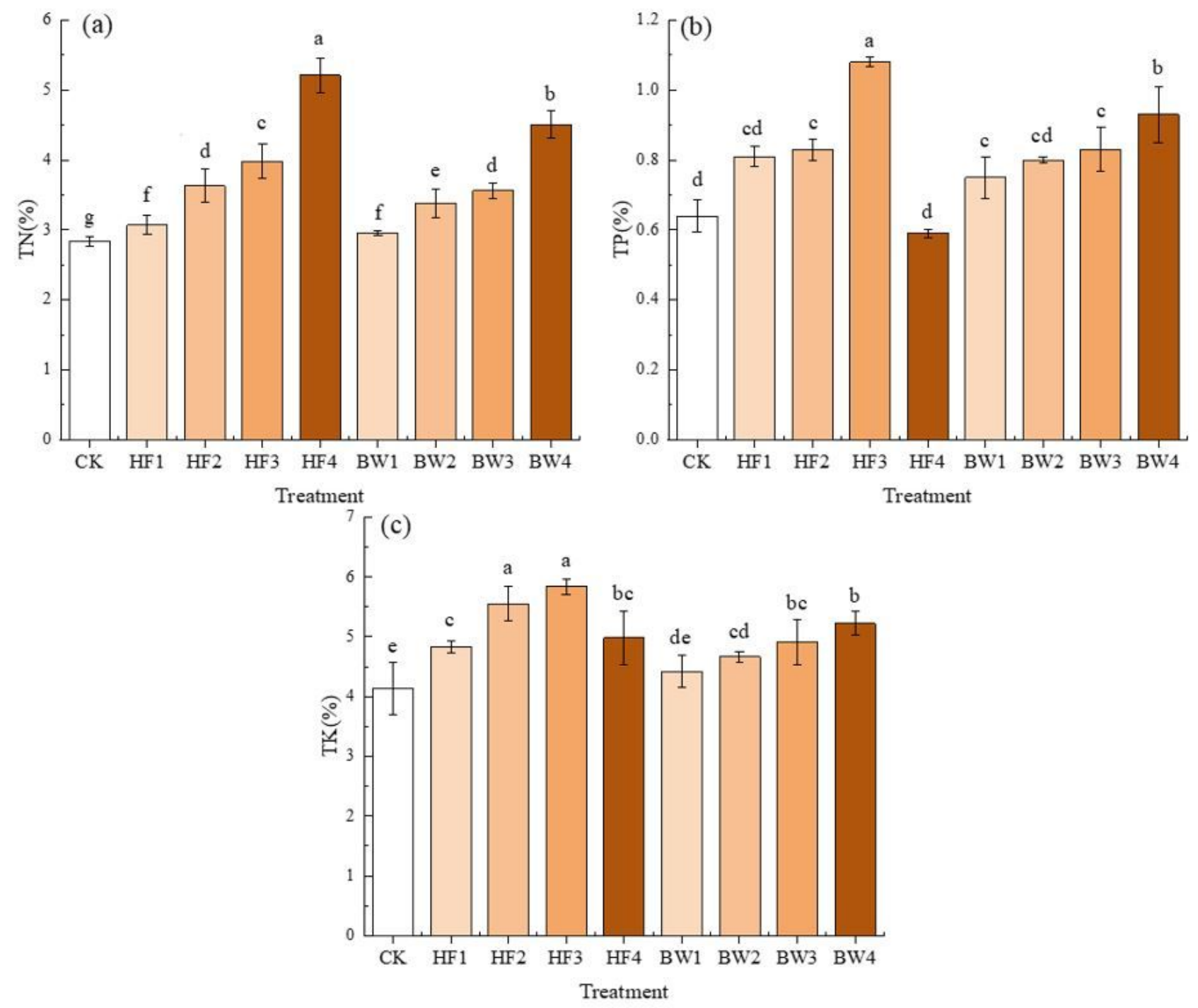

Figure 3

Effect of different treatments on nutrient accumulation of pakchoi: (a) TN; (b) TP; (c) TK. Mean values and standard deviations are shown $(n=3)$. Different letters above bars indicate significant difference at $p$ $<0.05$, based on Duncan's multiple range test. 

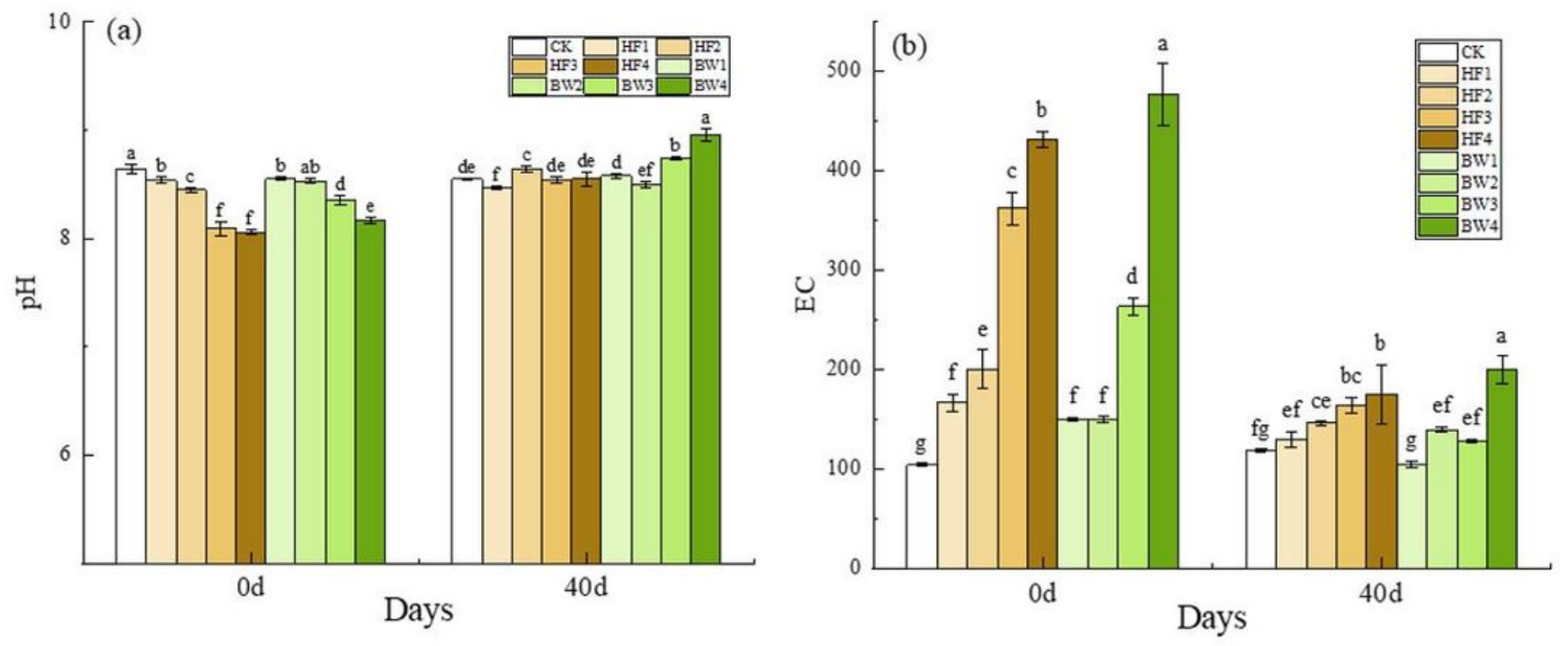

\section{Figure 4}

Effect of different treatments on soil basic properties before and after planting: (a) pH; (b) EC. Mean values and standard deviations are shown $(n=3)$. Different letters above bars indicate significant difference at $p<0.05$, based on Duncan's multiple range test. 

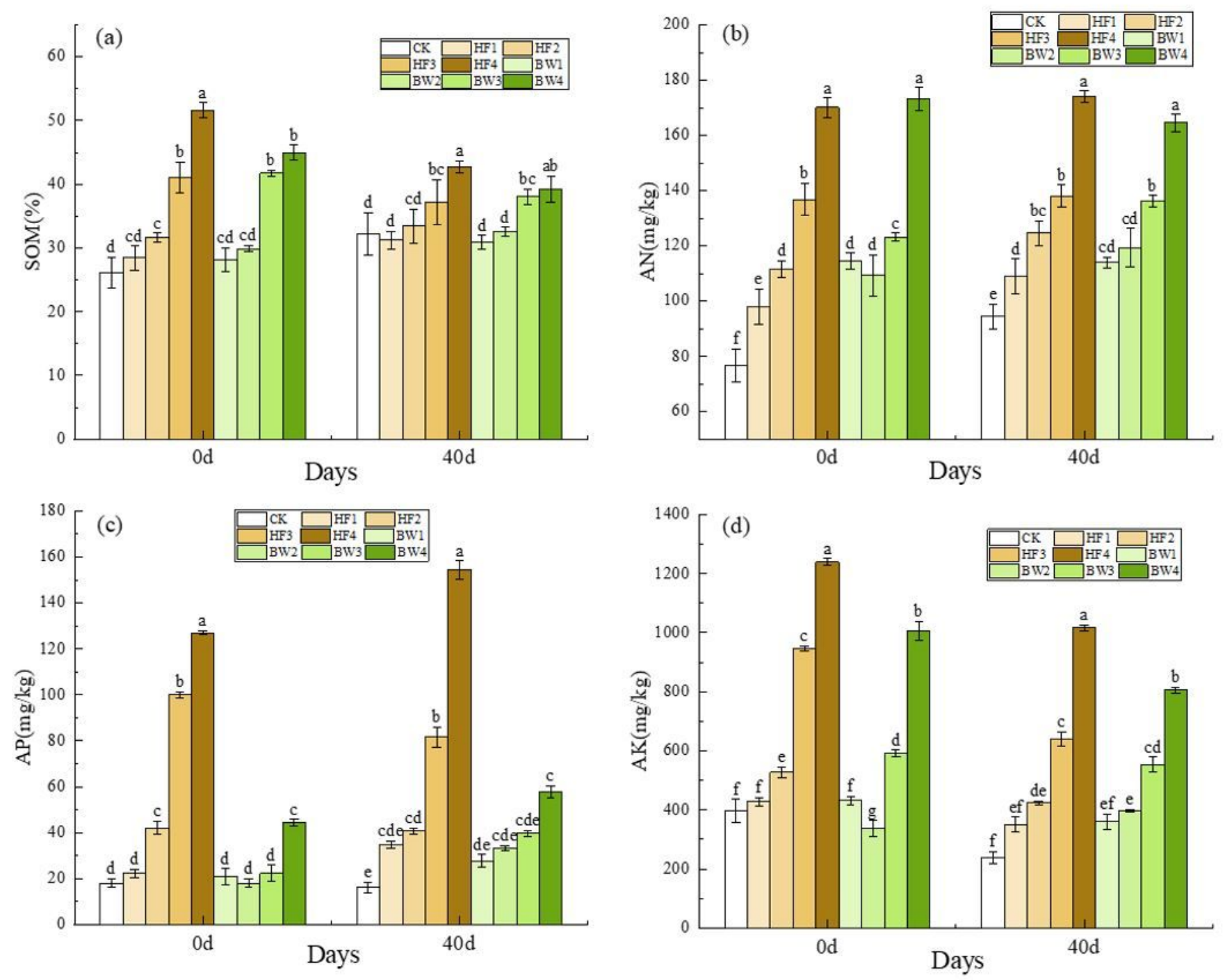

Figure 5

Effect of different treatments on soil nutrient content before and after planting: (a) SOM; (b) AN; (c) AP; (d) AK. Mean values and standard deviations are shown $(n=3)$. Different letters above bars indicate significant difference at $p<0.05$, based on Duncan's multiple range test. 

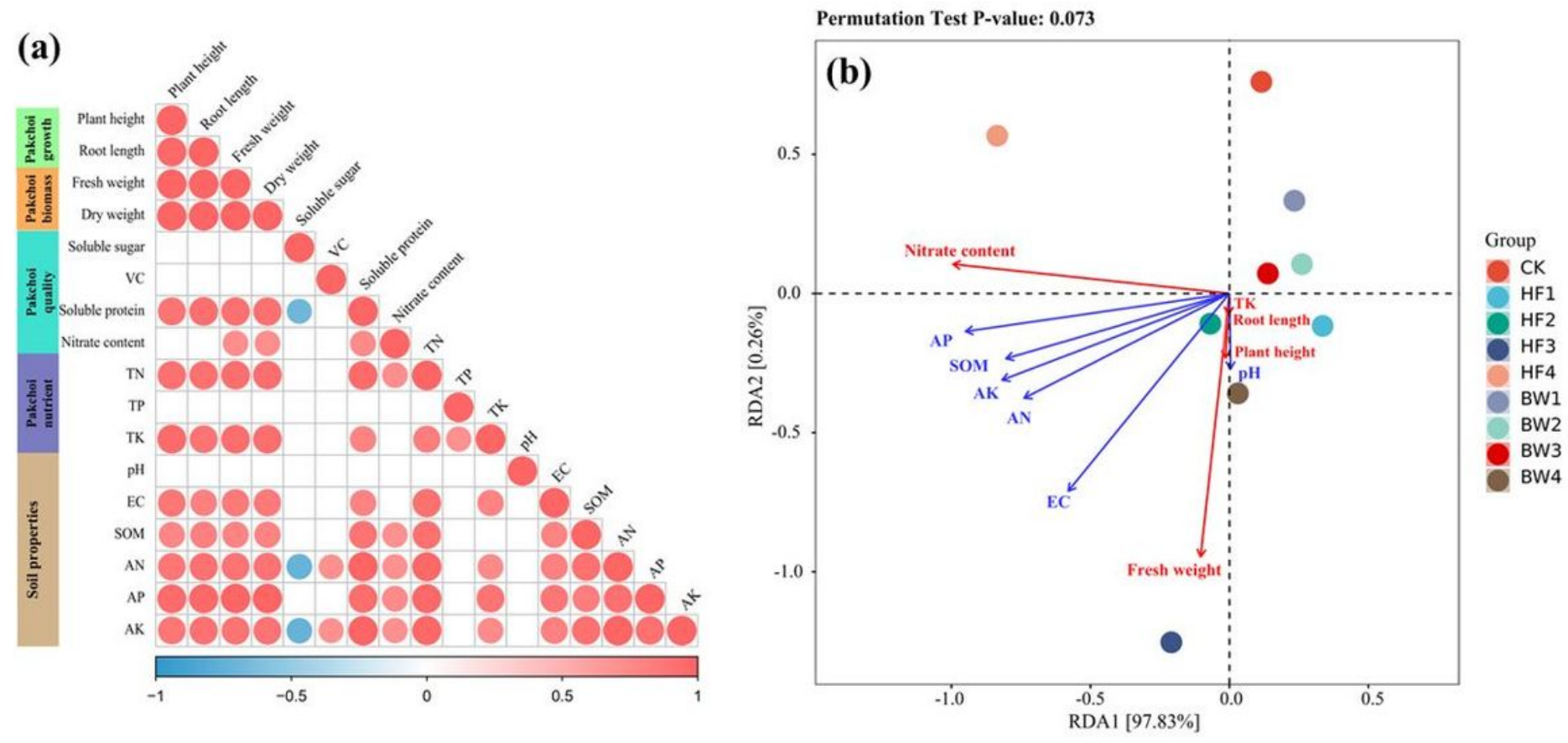

Figure 6

Correlations between soil properties and physiological characteristics of pakchoi: (a) Spearman correlation analysis. Red represents a positive correlation $(p<0.05)$, blue represents a negative correlation ( $p<0.05$ ), and color depth represents the strength of the correlation; (b) Redundancy analysis (RDA) used to assess the relationship among soil physicochemical factors (blue arrows) and physiological characteristics of pakchoi (red arrows). Correlations between environmental variables and RDA axes are represented by the lengths and angles of arrows. 